NBER WORKING PAPER SERIES

\title{
CAPITAL CONTROLS OR MACROPRUDENTIAL REGULATION?
}

\author{
Anton Korinek \\ Damiano Sandri \\ Working Paper 20805 \\ http://www.nber.org/papers/w20805 \\ NATIONAL BUREAU OF ECONOMIC RESEARCH \\ 1050 Massachusetts Avenue \\ Cambridge, MA 02138 \\ December 2014
}

The views expressed herein are those of the authors and should not be attributed to the IMF, its Executive Board, its management, or the National Bureau of Economic Research. We thank Larry Ball, Suman Basu, Marcos Chamon, Giovanni Dell'Ariccia, Pierre-Olivier Gourinchas, Sebnem Kalemli-Ozcan, Luc Laeven, Albert Martin, and Joseph Stiglitz as well as participants at the CBRT-NBER-pre-conference and at a seminar at the IMF for helpful comments and suggestions and Olivier Blanchard, Rex Ghosh and Jonathan Ostry for detailed discussions on the topic. Korinek acknowledges financial support from the IMF Research Fellowship and from CIGI/INET.

NBER working papers are circulated for discussion and comment purposes. They have not been peerreviewed or been subject to the review by the NBER Board of Directors that accompanies official NBER publications.

(C) 2014 by Anton Korinek and Damiano Sandri. All rights reserved. Short sections of text, not to exceed two paragraphs, may be quoted without explicit permission provided that full credit, including (C notice, is given to the source. 
Capital Controls or Macroprudential Regulation?

Anton Korinek and Damiano Sandri

NBER Working Paper No. 20805

December 2014

JEL No. E44,F34,F41

\begin{abstract}
$\underline{\text { ABSTRACT }}$
We examine the effectiveness of capital controls versus macroprudential regulation in reducing financial fragility in a small open economy model in which there is excessive borrowing because of externalities associated with financial crises and contractionary exchange rate depreciations. We find that both types of instruments play distinct roles: macroprudential regulation reduces the indebtedness of leveraged borrowers whereas capital controls induce more precautionary behavior for the economy as a whole, including for savers. This reduces crisis risk by shoring up aggregate net worth and mitigating the transfer problem that occurs during crises. In advanced countries where the risk of large contractionary depreciations is more limited, the role for capital controls subsides. However, macroprudential regulation remains essential in our model to mitigate booms and busts in asset prices.
\end{abstract}

\author{
Anton Korinek \\ Department of Economics \\ Johns Hopkins University \\ 440 Mergenthaler Hall \\ 3400 N. Charles Street \\ Baltimore, MD 21218 \\ and NBER \\ akorinek@jhu.edu \\ Damiano Sandri \\ International Monetary Fund \\ 700 19th Street N.W. \\ Washington D.C. 20431 \\ dsandri@imf.org
}




\section{Introduction}

In the aftermath of the Great Financial Crisis of 2008/09 many emerging economies have experienced large capital inflows and have struggled to define an optimal policy response. Policymakers have resorted to capital controls and macroprudential regulation to lean against the risks created by capital inflows. Both types of financial market interventions place restrictions on financial flows between creditors and debtors, typically with the goal of enhancing macroeconomic stability. ${ }^{1}$

The defining feature of capital controls is that they apply exclusively to financial transactions between residents and non-residents, i.e. they discriminate based on the residency of the parties involved in a financial transaction. ${ }^{2}$ For example, controls on capital inflows apply to transactions between foreign creditors and domestic debtors. Similarly, controls on capital outflows apply to transactions between domestic savers and international borrowers. Capital controls segment domestic and international financial markets, as illustrated in the left panel of Figure 1. As a result of this segmentation, international lenders and domestic agents face different effective interest rates.

Macroprudential policies, by contrast, restrict borrowing by domestic agents independently of whether credit is provided by domestic or foreign creditors. They impose a segmentation between borrowers and all types of lenders, as illustrated in the right panel of 1 . As a result. borrowers and lenders in the economv face different effective interest rates. ${ }^{3}$

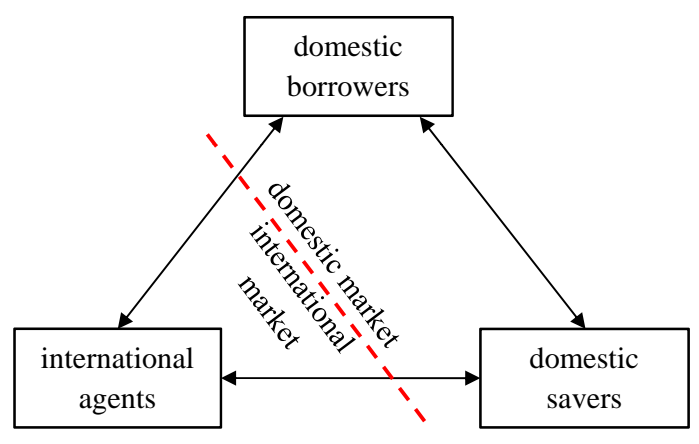

Capital Controls

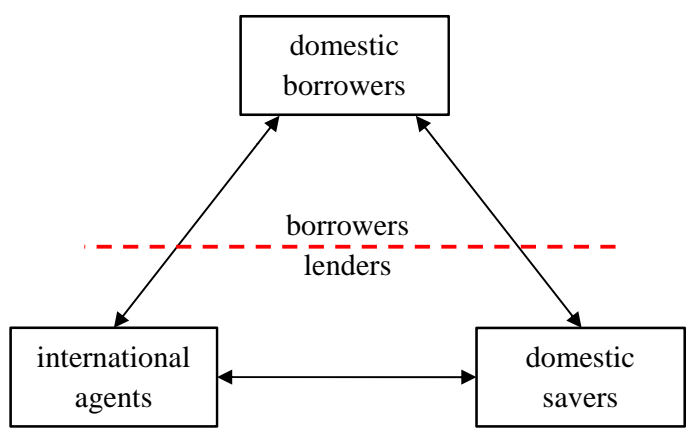

Macroprudential Regulation

Figure 1: Capital Controls Versus Macroprudential Regulation

\footnotetext{
${ }^{1}$ See e.g. Ostry et al. (2011) for capital controls and Galati and Moessner (2013) for macroprudential regulation. See also Ostry et al. (2014) for a detailed analysis of the policy considerations involved in choosing between capital controls and macroprudential regulation.

${ }^{2}$ More recently, the IMF (2012) has adopted the term capital flow management measures (CFMs) for capital controls, since the latter term has traditionally had a negative connotation. In this paper, we use the term capital controls in accordance with the tradition in the academic literature.

${ }^{3}$ In some instances, it is difficult to distinguish between capital controls and macroprudential regulation because regulators want to restrict borrowing in general (i.e. from both foreigners and domestic agents), but the only instrument that they have to restrict the borrowing from foreigners is a restriction on the capital account. Such a measure just places foreign and domestic creditors on equal footing and therefore does not represent a capital control as we defined it in the preceding paragraph, although others may define it as a capital control. We assume away targeting problems in the current paper and assume that regulators have both an effective macroprudential instrument and an effective capital controls at their disposal. For a more detailed analysis of targeting problems see e.g. Ostry et al. (2014).
} 
Should countries use capital controls or macroprudential regulation when they experience large credit growth? Some have argued that capital controls should only be used as a measure of last resort (see e.g. IMF, 2012). Others, by contrast, have argued that capital controls are the more natural instrument when credit growth is mainly driven by capital flows from abroad (see e.g. Ostry et al., 2011). Should the two policy instruments be thought of as equivalent? Or alternatively, does each of the two have its own comparative advantage depending on specific circumstances?

We analyze these issues in a model of a small open economy with pecuniary externalities arising from collateral constraints. The key departure from the existing literature is that we explicitly account for the presence of both domestic and foreign creditors in order to distinguish between capital controls and macroprudential measures. As can be easily seen in Figure 1, capital controls and macroprudential regulations are equivalent in models that feature only either domestic or foreign lenders. In our framework, the main difference between domestic and foreign lenders is that the latter do not consume domestic nontraded goods; therefore a transfer of resources between domestic and foreign agents affects spending on domestic goods and the real exchange rate, giving rise to a transfer problem. ${ }^{4}$

To introduce financial fragility and crises in our model, we assume a collateral constraint that limits the borrowing capacity of domestic borrowers. Critically, this constraint depends on the level of the exchange rate, reflecting that part of the collateral of domestic borrowers is consists of non-tradable goods. As a result, the borrowing capacity of the economy is lowest when domestic borrowers are poorest and would most like to borrow.

We equate equilibria with binding financial constraints on borrowers with financial crises. When financial constraints bind, the economy experiences the classic dynamics of sudden stops and financial amplification (see e.g. Korinek and Mendoza, 2014). Domestic demand by constrained agents declines, leading to capital outflows and the depreciation of the exchange rate that further tightens borrowing constraints. This triggers the feedback loop illustrated in Figure 2 which leads to a sharp reduction in domestic aggregate demand, a large exchange rate depreciation, and a reversal in the current account.

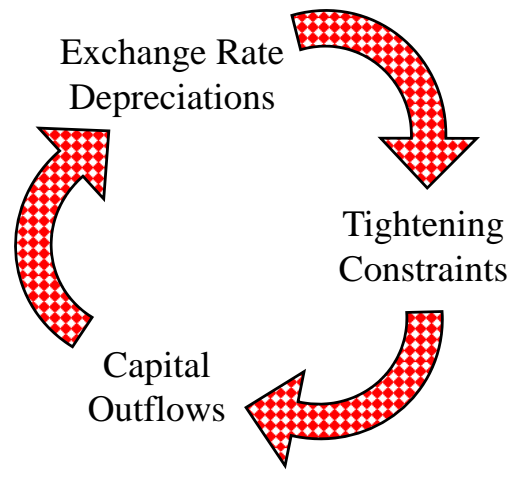

Figure 2: Feedback loop of financial crises with exchange rate depreciations

The East Asian crisis in 1997 provides a clear example of the extreme dynamics of a

\footnotetext{
${ }^{4}$ The transfer problem associated with large international capital flows was first identified in a debate by Keynes (1929) and Ohlin (1929) on the economic effects of German World War I reparations on the country's exchange rate and ability to pay.
} 
sudden stop. Figure 3 shows that East Asian countries experienced a dramatic contraction in GDP, on average of about 10 percent. ${ }^{5}$ The fall in GDP was associated with a sudden reversal of the current account that adjusted by more than 10 percentage points of GDP within one year. Meanwhile the economy witnessed a sharp correction of the real exchange rate that collapsed by about 25 percent This severely impaired the balance sheets of borrowers and constrained their ability to raise new loans.
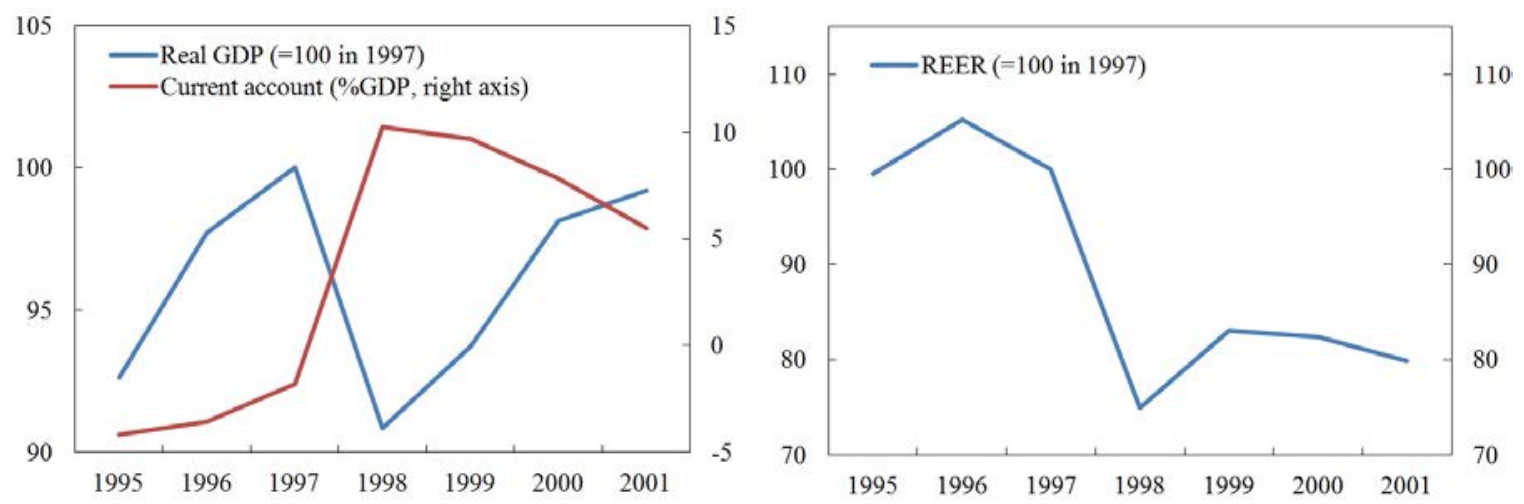

Figure 3: Sudden stop dynamics: the East Asian crisis of 1997.

To understand the role of capital controls and macroprudential regulation, we compare the decentralized equilibrium in the described model economy with the allocations of a social planner who determines the intertemporal allocations of domestic borrowers and savers. We show that exchange rate depreciations in financially fragile emerging economies are associated with pecuniary externalities: depreciations that tighten financial constraints lead to an inefficient reallocation of liquid wealth from constrained borrowers with a high marginal valuation of wealth to lenders with a lower relative valuation of wealth. Since private agents take prices as given, they take the tightness of constraints as given when choosing their optimal behavior. By contrast, the social planner recognizes that precautionary actions such as reduced borrowing in the run-up to a financial crisis lead to a first-order welfare gain if a financial crisis hits because they mitigate the transfer problem, the exchange rate decline, and the tightness of binding constraints. At the same time, the envelope theorem implies that these actions come only at a second-order cost during the run-up to a crisis because they constitute deviations from optimal smoothing. As a result, a planner engages in more precautionary actions than private agents. In short, the pecuniary externalities from exchange rate depreciations are welfare-relevant in financially fragile emerging economies; the competitive equilibrium is constrained inefficient and there is a case for policy intervention.

In particular, the goal of a social planner is to contain the depreciation of the exchange rate during crises by supporting domestic demand for non-traded goods. To this end, the planner raises the net worth of both domestic borrowers and savers since they both have a positive marginal propensity to consume. Both capital controls and macroprudential measures are needed to implement constrained efficient allocations. Capital controls are needed because the planner wants to increase the domestic interest rate above the world interest rate in order to shore up the net worth of all domestic agents including savers, i.e. she

\footnotetext{
${ }^{5}$ East Asian countries include Indonesia, Malaysia, Philippines, South Korea and Thailand.
} 
wants to both curb domestic borrowing and encourage domestic saving. Macroprudential measures are needed because the planner wants to shore up the net worth of borrowers even more than that of domestic savers since borrowers are constrained and therefore have a higher marginal propensity to consume than domestic savers. Macroprudential measures on top of capital controls allow the planner to implement this different policy treatment of borrowers and savers.

We show in a number of specific model settings that there are benefits to combining capital controls and macroprudential regulation. For ease of exposition, we first model an emerging economy that will suffer a financial crisis with perfect foresight. In this setting, we show that a policymaker would want to impose both measures to reduce borrowing and increase saving. We then show that our results continue to hold if we introduce uncertainty into the model: if domestic agents have access to state-contingent financial instruments, the described externality induces private agents to take on excessive risk and insure too little. A planner uses capital controls and macroprudential regulation to remedy this.

In an extension, we introduce an economy in which financial constraints and pecuniary externalities are not driven by the exchange rate but by asset prices. When borrowing capacity is linked to asset prices and constrained borrowers have a more efficient use for assets than unconstrained savers, an economy can experience a vicious cycle in which fire sales and asset price declines play a similar role to exchange rate depreciations in our earlier model of emerging economies. The vicious cycle takes place because binding constraints reduce borrowers' demand for assets, which in turn leads to fire sales, lower prices, and tightening borrowing constraints.

In a model of asset price externalities, we show that a social planner would support the demand for assets by shoring up the net worth of borrowers but not that of savers. Since savers are unconstrained, Fisherian separation holds between their consumption and investment decisions. Therefore, the demand for assets by savers is not a function of their net worth, and the social planner only intervenes to shore up the net worth of borrowers. Macroprudential regulation is thus sufficient to implement the planner's allocation and capital controls are no longer needed.

This suggests that the optimal mix of capital controls and macroprudential regulation in our model changes as an economy becomes more developed. Concerns about exchange rate volatility are particularly acute in emerging markets, especially those that have significant debts in foreign currency. In advanced economies, by contrast, the exchange rate is typically less relevant for financial stability, but asset price volatility and the associated pecuniary externalities remain a threat to financial stability. In our model, the benefits to imposing capital controls thus subside as an emerging economy becomes more advanced.

Literature There has been a growing academic literature both on macroprudential policies and on capital controls. For a survey of the emerging literature on capital controls see for example Korinek (2011a). For a survey on macroprudential regulation see for example Galati and Moessner (2013). This paper is the first to cover the intersection of the two types of policies.

An important strand of both branches of literature motivates macroprudential regulation and capital controls based on the existence of pecuniary externalities in the spirit of Geanakoplos and Polemarchakis (1986) and Greenwald and Stiglitz (1986). For example, 
Korinek (2007, 2010), Bianchi (2011) and Benigno et al (2012) develop models of foreign borrowing subject to collateral constraints and pecuniary externalities in the exchange rate that make the case for taxes on borrowing. Jeanne and Korinek (2010ab) and Bianchi and Mendoza (2013) analyze models in which borrowing is collateralized by assets and therefore vulnerable to pecuniary externalities in asset prices, making the case for restrictions on borrowing. However, none of these papers have distinguished between macroprudential regulation and capital controls: they analyze simple model structures in which there is a single type of domestic borrowers and international lenders; therefore there is no difference between macroprudential policy or capital controls - both are simply restrictions on borrowing. ${ }^{6}$ Our paper develops a framework in which there is a meaningful distinction between the two. This allows us to investigate the comparative advantages of the two types of prudential instruments and provide policy lessons for when it is optimal to use which instrument.

An alternative strand of literature motivates macroprudential regulation or capital controls based on aggregate demand externalities in the presence of nominal frictions and limitations on the use of monetary policy. Farhi and Werning (2013) present a general treatment of such aggregate demand externalities. Schmitt-Grohe and Uribe (2012) show that there is a case for macroprudential policy in a monetary union when there is downward rigidity in prices. Korinek and Simsek (2014) analyze the case for macroprudential taxes on leverage to mitigate liquidity traps that are driven by deleveraging. Farhi and Werning $(2012,2014)$ investigate the role for capital controls when monetary policy is unable to manage aggregate demand because of restrictions stemming from fixed exchange rates or because of stickiness in both prices and wages.

The empirical evaluation of capital controls and macroprudential policy measures is complicated by endogeneity problems - countries often tighten controls during booms in capital and credit flows, but the resulting positive correlation does not imply that the booms are caused by prudential measures. Magud et al. (2011) discuss the endogeneity problem arising in the evaluation of capital controls and conduct a meta-analysis of 34 empirical papers. They conclude that capital controls can make monetary policy more independent, change the composition of inflows, and reduce exchange rate pressure under certain circumstances. Claessens et al. (2013) analyze what types of macroprudential policy instruments are most effective at curbing credit booms by looking at their effects on the balance sheets of financial institutions. Federico et al. (2013) evaluate the effectiveness of cyclical macroprudential policies using a narrative approach to identify exogenous variation. Forbes et al. (2013) evaluate the effectiveness of capital controls and macroprudential measures and address the endogeneity bias using a propensity-score matching technique. Alfaro et al. (2014) analyze the effects of capital controls on firm investment and show how they interact with firm-level liquidity constraints.

\footnotetext{
${ }^{6}$ Jeanne (2014) presents a framework of optimal macroprudential regulation in which capital controls are by construction a second-best device and focuses on the implications for international policy cooperation. He observes, however, that capital controls may be desirable in addition to macroprudential regulation if credit flows from foreigners impose greater externalities than purely domestic credit flows, as is the case in our framework.
} 


\section{Model}

\subsection{Setup}

We consider a small open economy with three time periods $t \in\{0,1,2\}$. There is a unit mass of domestic borrowers $B$ and a unit mass of domestic savers $S$ in the economy. Furthermore, there is a large set of foreigners $F$ who trade bonds (i.e. lend or borrow) at an exogenous interest rate of 1 . The two types of domestic agents $i \in\{B, S\}$ derive utility from the consumption $c_{T}^{i}$ of traded goods and $c_{N}^{i}$ of non-traded goods. For simplicity, they consume non-traded goods only in period 1 so that their overall utility is given by,

$$
U^{i}=u\left(c_{T, 0}^{i}\right)+u\left(c_{1}^{i}\right)+u\left(c_{T, 2}^{i}\right)
$$

where the period utility functions $u(c)=\ln c$ and where $c_{1}^{i}=\left(c_{T, 1}^{i}\right)^{\alpha}\left(c_{N, 1}^{i}\right)^{1-\alpha}$ is a consumption index of traded and non-traded goods with relative expenditure shares $\alpha$ and $1-\alpha$. We omit non-traded goods in periods 0 and 2 to simplify our analysis.

In period 0 , domestic agents use an endowment of traded goods $y_{T, 0}^{i}$ to consume and purchase $b_{1}^{i}$ units of bonds, where $b<0$ corresponds to borrowing,

$$
c_{T, 0}^{i}+b_{1}^{i}=y_{T, 0}^{i}
$$

In period 1, agents receive endowments of traded and non-traded goods $\left(y_{T, 1}^{i}, y_{N, 1}^{i}\right)$. Agents also receive an endowment of traded goods $y_{T, 2}^{i}$ at time 2 .

We denote the relative price of non-traded to traded consumption goods by $p$ and observe that $p$ also represents a measure of the country's real exchange rate. ${ }^{7}$ The period 1 budget constraint of an agent $i \in\{B, L\}$ is

$$
c_{T, 1}^{i}+p c_{N, 1}^{i}+b_{2}^{i}=y_{T, 1}^{i}+p y_{N, 1}^{i}+b_{1}^{i}
$$

where $b_{2}^{i}$ is the amount of bonds carried into the following period.

In period 2, agents finance their consumption using the traded endowment $y_{T, 2}^{i}$ and the bonds carried into the period,

$$
c_{T, 2}^{i}=y_{T, 2}^{i}+b_{2}^{i}
$$

The endowments of domestic borrowers and savers are distributed such that in periods 0 and 1 borrowers find it optimal to borrow, $b_{t}^{B}<0$, and savers find it optimal to save, $b_{t}^{S}>0$.

Financial constraint We introduce a financial constraint on borrowers as in Mendoza (2006) that is motivated by the commitment problem described in Korinek (2010): After borrowers have received their loans in period 1, we assume they have an opportunity to divert their income and renege on their borrowing. However, lenders can take them to court

\footnotetext{
${ }^{7}$ A country's real exchange rate is commonly defined as the price of a basket of domestic consumption goods in terms of a basket of international consumption goods. In accordance with our small open economy assumption, we take the price of international consumption goods and traded domestic consumption goods as exogenous. Therefore the price of a domestic consumption basket is a strictly increasing function of the relative price of domestic non-traded goods.
} 
and recover up to a fraction $\phi$ of their period 1 income. To rule out default, borrowing $-b_{2}^{B}$ is limited to

$$
-b_{2}^{B} \leq \phi\left(y_{T, 1}^{B}+p y_{N, 1}^{B}\right)
$$

Broadly speaking, we interpret the coefficient $\phi$ as a pledgeability parameter. ${ }^{8}$

This type of financial constraint (5) is common in the literature on emerging market crises. The relative price $p$ that appear in the constraint generates both financial amplification effects and pecuniary externalities. As we will show below, financial amplification effects occur because when the constraint is binding, borrowers need to reduce consumption which leads to real exchange rate depreciations that tighten the constraint further. Pecuniary externalities occur because individual agents do not take into account how their decisions affect the real exchange rate and the tightness of the constraint.

The strength of financial amplification depends crucially on the parameter $\phi$. For $\phi=0$, there will be no amplification since the borrowing limit is constant. The higher $\phi$, the greater the amplification effects. To ensure that the economy in our model is well-behaved and that financial amplification effects are bounded, we impose

Assumption $1 \phi<\hat{\phi}$.

where the upper limit $\hat{\phi}$ is characterized in Appendix A.1. This is a common assumption in all models of financial amplification and imposes only mild restrictions (see e.g. the detailed discussion in section 3.2 of Korinek and Mendoza, 2014).

\subsection{Decentralized Equilibrium}

An equilibrium in the described economy consists of a set of allocations and prices in which each agent $i \in\{B, S\}$ maximizes her utility (1) subject to the budget constraints (2), (3) and (4) as well as the financial constraint (5) and in which markets for nontraded goods clear

$$
\sum_{i}\left(C_{N, 1}^{i}-Y_{N, 1}^{i}\right)=0
$$

In this definition, we follow the convention of denoting aggregate variables by upper-case letters, e.g. $C_{N, 1}^{i}$ is aggregate nontraded consumption and so forth. Market clearing for traded goods is ensured by the domestic budget constraints together with the fact that foreign agents can satisfy any amount of borrowing or lending by domestic agents.

We solve for the equilibrium via backward induction. It proves useful to express the period 1 welfare of domestic agents $i \in\{B, S\}$ as a function of their period 1 liquid net worth, defined as the period 1 endowment of traded goods plus bond holdings,

$$
m^{i}=y_{T, 1}^{i}+b_{1}^{i}
$$

We observe that the aggregate state of the economy in period 1 is fully described by the aggregate liquid net worth positions of the two sets of domestic agents $\left(M^{B}, M^{S}\right)$. In

\footnotetext{
${ }^{8}$ We could refine this constraint by assuming different degrees of pledgeability for traded and non-traded goods but this is not essential to our analysis. We could also impose an equivalent constraint on period 0 borrowing $b_{1}^{i}$ but the model solution would be degenerate if this constraint is binding - all the interesting decisions of borrowers are pre-determined by binding constraints. Without loss of generality, we focus on equilibria in which the period 0 constraint is loose.
} 
equilibrium, $m^{i}=M^{i}$ will hold but private agents do not internalize their impact on aggregate variables when making their optimal choices.

An agent $i \in\{B, S\}$ takes the state of the economy $\left(M^{B}, M^{S}\right)$ as given and solves the utility maximization problem

$$
\begin{aligned}
& \max _{b_{1}^{i}} u\left(y_{T, 0}^{i}-b_{1}^{i}\right)+V^{i}\left(m^{i} ; M^{B}, M^{S}\right) \\
& \text { where } V^{i}\left(m^{i} ; M^{B}, M^{S}\right)=\max _{b_{2}^{i}, c_{T, 1}^{i}, c_{N, 1}^{i}, c_{T, 2}^{i}} u\left(c_{T, 1}^{i}, c_{N, 1}^{i}\right)+u\left(y_{T, 2}^{i}+b_{2}^{i}\right)+ \\
& \quad+\mu^{i}\left[m^{i}+p\left(y_{N, 1}^{i}-c_{N, 1}^{i}\right)-c_{T, 1}^{i}-b_{2}^{i}\right]+\lambda^{i}\left[b_{2}^{i}+\phi\left(y_{T, 1}^{i}+p y_{N, 1}^{i}\right)\right]
\end{aligned}
$$

where we assigned the shadow prices $\mu^{i}$ and $\lambda^{i}$ to the period 1 budget constraint (3) and the borrowing constraint (5). The envelope condition implies that the marginal valuation of liquid net worth of individual agents satisfies

$$
\frac{\partial V^{i}}{\partial m^{i}}=u_{T, 1}^{i}
$$

where we denote by $u_{T, 1}^{i}=\partial u\left(c_{1}^{i}\right) / \partial c_{T, 1}^{i}$ the marginal utility of traded consumption in period 1 and similarly for $u_{T, 0}^{i}, u_{N, 1}^{i}$ and $u_{T, 2}^{i}$. The optimality conditions associated with the optimization problem yield two Euler equations

$$
\begin{aligned}
& u_{T, 0}^{i}=u_{T, 1}^{i} \\
& u_{T, 1}^{i}=u_{T, 2}^{i}+\lambda^{i}
\end{aligned}
$$

and where $\lambda^{i}$ is the shadow price on the borrowing constraint of agent $i$. Since domestic savers $S$ are not borrowing, we know that $\lambda^{S}=0$.

The optimality condition that relates period 1 traded and non-traded consumption delivers an expression for the exchange rate

$$
p=\frac{u_{N, 1}^{i}}{u_{T, 1}^{i}}=\frac{1-\alpha}{\alpha} \frac{c_{T, 1}^{i}}{c_{N, 1}^{i}}
$$

Since this condition has to hold for both domestic agents, we observe that we can add up the traded/non-traded consumption of both agents and combine the result with the market-clearing condition (6) for non-traded goods to obtain

$$
p=\frac{1-\alpha}{\alpha} \frac{C_{T, 1}^{B}+C_{T, 1}^{S}}{Y_{N, 1}}
$$

where $Y_{N, 1}=Y_{N, 1}^{B}+Y_{N, 1}^{S}$. In short, the real exchange rate is a strictly increasing function of aggregate tradable spending $\left(C_{T, 1}^{B}+C_{T, 1}^{S}\right)$.

\subsubsection{Characterizing the Decentralized Equilibrium}

Proceeding via backward induction, we first characterize the decentralized equilibrium in periods 1 and 2 and then analyze the optimal period 0 decisions. We separately analyze 
equilibrium when the financial constraint on borrowers is loose, corresponding to normal times, and when the financial constraint is binding, corresponding to crisis times. We define the set of state variables $\left(M^{B}, M^{S}\right)$ for which the economy is unconstrained by $\mathcal{M}^{\text {unc }}$ and the set for which they are constrained by $\mathcal{M}^{\text {con }}$; the two are mutually exclusive and are defined in Appendix A.1.

Unconstrained equilibria For unconstrained equilibria, i.e. for $\left(M^{B}, M^{S}\right) \in \mathcal{M}^{\text {unc }}$, all agents smooth consumption according to their Euler equation so that $u_{T, 1}^{i}=u_{T, 2}^{i}$ for $\forall i \in\{B, S\}$. Period 1 traded consumption of agent $i$ is given by

$$
c_{T, 1}^{i}=\frac{\alpha}{2}\left(m^{i}+p y_{N, 1}^{i}+y_{T, 2}^{i}\right)
$$

since the agent spends half of her income in period 1 and a fraction $\alpha$ thereof on traded goods. The exchange rate can be written as a simple function of $\left(M^{B}, M^{S}\right)$

$$
p\left(M^{B}, M^{S}\right)=\frac{1-\alpha}{1+\alpha} \frac{M^{B}+M^{S}+Y_{T, 2}^{B}+Y_{T, 2}^{S}}{Y_{N, 1}}
$$

This implies that an increase in the liquid net worth $M^{i}$ of either domestic agent pushes up the real exchange rate by

$$
\frac{\partial p}{\partial M^{B}}=\frac{\partial p}{\partial M^{S}}=\frac{1-\alpha}{Y_{N, 1}(1+\alpha)}>0
$$

Notice that the effects of borrowers and lenders' net worth on the real exchange rate are equal because the marginal propensity to consume (MPC) is identical for both agents when they are unconstrained. From equation (12), we can indeed derive

$$
M P C^{i}=\frac{\partial\left[c_{T, 1}^{i}+p c_{N, 1}^{i}\right]}{\partial m^{i}}=\frac{1}{2}
$$

Therefore, an increase in either agent's net worth equally stimulates aggregate domestic demand and appreciates the real exchange rate.

Constrained equilibria For constrained equilibria, i.e. for $\left(M^{B}, M^{S}\right) \in \mathcal{M}^{\text {con }}$, the level of traded consumption of borrowers is determined by the binding constraint (5) and is given by

$$
c_{T, 1}^{B}=\alpha\left[m^{B}+p y_{N, 1}^{B}+\phi\left(y_{T, 1}^{B}+p y_{N, 1}^{B}\right)\right]
$$

In short, borrowers spend a fraction $\alpha$ of their liquid net worth on traded goods. Spending on traded goods by savers is still given by condition (12). We can use the two expressions to express the real exchange rate in (11) as a linear function of $\left(M^{B}, M^{S}\right)$ that is given by

$$
p\left(M^{B}, M^{S}\right)=\frac{1-\alpha}{D}\left(M^{B}+\phi Y_{T, 1}^{B}+\frac{M^{S}+Y_{T, 2}^{S}}{2}\right)
$$

where $D=Y_{N, 1}-(1-\alpha)\left[Y_{N, 1}^{B}(1+\phi)+Y_{N, 1}^{S} / 2\right]>0$ is strictly positive under our Assumption $1, \phi<\hat{\phi}$. 
In the constrained region, an increase in either agent's net worth raises the real exchange rate. However, differently from the unconstrained region, an increase in borrowers' net worth has a twice as strong effect as an increase in savers' net worth

$$
\frac{\partial p}{\partial M^{B}}=\frac{1-\alpha}{D}>\frac{\partial p}{\partial M^{S}}=\frac{1-\alpha}{2 D}>0
$$

The reason for the different impact of borrowers' and savers' net worth lies in the different marginal propensity to consume. Facing a binding constraint, borrowers' MPC is now twice as high as under the unconstrained solution. Using equation (13), we indeed observe that

$$
M P C^{B}=1>M P C^{S}=\frac{1}{2}
$$

Figure 4 schematically depicts the response of the exchange rate $p$ to varying the level of $M^{B}$ for two different levels of the net worth of savers $M^{S}$. For each level of $M^{S}$, there is a threshold value of $M^{B}$ below which the equilibrium becomes constrained, indicated by the vertical dashed lines. In the constrained region, i.e. to the left, the exchange rate responds strongly to changes in $M^{B}$ since financial amplification effects are at play: additional net worth allows borrowers to demand more non-traded goods, which pushes up their prices and relaxes the financial constraint, leading to a virtuous cycle of rising prices and loosening of the constraint.
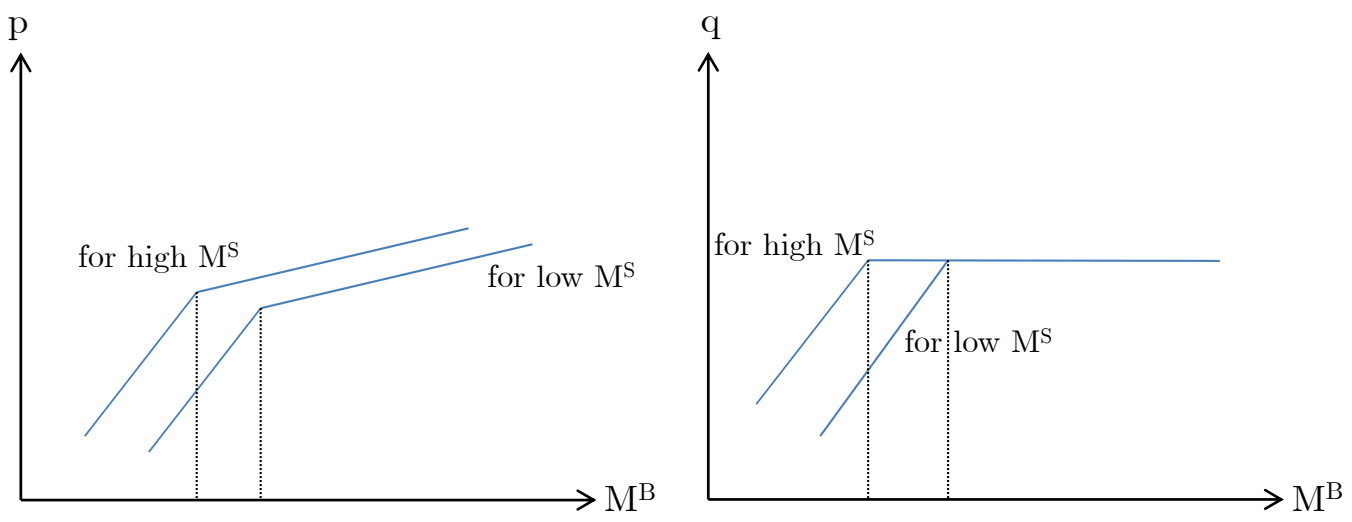

Figure 4: Exchange rate $p$ as a function of $M^{B}$

Lemma 1 (i) The economy's real exchange rate is an increasing function of period 1 spending on traded goods, which in turn is an increasing function of both net worth $M^{B}$ and $M^{S}$.

(ii) If the economy is unconstrained, then $\partial p / \partial M^{B}=\partial p / \partial M^{S}>0$.

(iii) If the economy is constrained, then $\partial p / \partial M^{B}>\partial p / \partial M^{S}>0$

Proof. See discussion above.

Comparative statics of net worth $M^{i}$. For our subsequent analysis, it proves useful to analyze how the welfare of the two types of domestic agents is affected by changes in 
aggregate liquid net worth. Taking the derivative of the value function of agent $j$ with respect to the aggregate net worth $M^{i}$ of agent $i$ we see that:

$$
\frac{\partial V^{j}}{\partial M^{i}}=u_{T, 1}^{j} \cdot \underbrace{\frac{\partial p}{\partial M^{i}}\left(y_{N, 1}^{j}-c_{N, 1}^{j}\right)}_{\text {redistribution between agents } R_{i}^{j}}+\lambda^{j} \cdot \underbrace{\frac{\partial p}{\partial M^{i}} \phi y_{N, 1}^{j}}_{\text {relaxation of constraint } \Phi_{i}^{j}}
$$

We observe that changes in aggregate $M^{i}$ affect the welfare of agent $j$ solely through changes in the price of non-traded goods $\partial p / \partial M^{j}$, i.e through pecuniary externalities. All other variables are either exogenous or optimally chosen by private agents, which allows us to apply the envelope theorem and omit any associated derivatives in expression (15).

We distinguish the pecuniary externalities that arise from changes in $M^{i}$ into two parts: The first part corresponds to the first term in equation (15), which we denote by $R_{i}^{j}$, and reflects that price changes create redistributions between agents. Since non-traded goods are only traded among domestic agents, the redistributions between domestic agents always net out, i.e. $R_{i}^{i}+R_{i}^{j}=0$. If agent $j$ is a net seller of non-traded goods $\left(y_{N, 1}^{j}>c_{N, 1}^{j}\right)$ then an increase in the price of the good benefits agent $j$ and vice versa.

The second part corresponds to the second term in equation (15), which we denote with $\Phi_{i}^{j}$, and reflects that price changes affect the tightness of collateral constraints in the economy. An increase in the exchange rate relaxes collateral constraints which provides a welfare benefit $\lambda^{j}$.

For our model to be well-behaved, we impose the following assumption on the redistributive terms:

Assumption $21+R_{B}^{B}-R_{S}^{B}>0$.

This rules out "immiserizing" transfers, i.e. it ensures that transferring one dollar from savers to borrowers does not lead to price changes that reduce borrowers' wealth.

\subsection{Constrained Planning Problem}

A social planner in the described economy maximizes the weighted sum of welfare of domestic agents in the economy, subject to the economy's resource constraints. Since international lenders are indifferent between lending or borrowing, their utility is unaffected by the allocations in the domestic economy, and they can be omitted from the planning problem. By implication, any Pareto efficient allocation in the domestic economy is also a Pareto efficient global allocation.

We focus on a constrained planning problem in which the allocations of the planner are subject to the same financial constraint (5) as the allocations of private agents. Following the tradition of Stiglitz (1981) and Geanakoplos and Polemarchakis (1986), we assume that the constrained planner can pick the financial allocations of domestic agents in period 0 and that she leaves the remaining allocations in periods 1 and 2 to be determined by decentralized agents. This implies that the planner takes it as given that the exchange rate is determined in decentralized markets according to condition (11), capturing the notion 
that it is commonplace for policymakers to impose financial regulation that restricts borrowing/lending, but that it is difficult for them to directly set the level of exchange rates in financial markets without giving rise to massive arbitrage behavior. ${ }^{9}$

The constrained planner chooses the optimal period 0 allocations while internalizing how the aggregate period 1 state variables, i.e. the aggregate liquid net worth positions $\left(M^{B}, M^{S}\right)$ of domestic agents, affect equilibrium and welfare in the economy in periods 1 and 2. Specifically, the constrained social planner maximizes the weighted sum of domestic social welfare with weights $\gamma^{i}, i \in\{B, S\}$, subject to the period 0 resource constraint of the economy,

$$
\max _{C_{T, 0}^{i}, B_{1}^{i}} \sum_{i \in\{B, S\}} \gamma^{i}\left\{u\left(C_{T, 0}^{i}\right)+V^{i}\left(m^{i} ; M^{B}, M^{S}\right)\right\} \quad \text { s.t. } \sum_{i \in\{B, S\}}\left(C_{T, 0}^{i}+B_{1}^{i}-Y_{T, 0}^{i}\right) \leq 0
$$

where she internalizes that $m^{i}=M^{i}=Y_{T, 1}^{i}+B_{1}^{i}$. By varying the welfare weights, we can trace the entire Pareto frontier of the economy. The continuation utility of private agents of type $i \in\{B, S\}$ from time 1 onwards is given by the value function $V^{i}\left(m^{i} ; M^{B}, M^{S}\right)$ that we characterized in equation (7) in the decentralized equilibrium.

\section{Characterizing the Planning Solution}

Using the envelope condition $\partial V^{i} / \partial m^{i}=u_{T, 1}^{i}$, the planner's optimality conditions are

$$
\begin{aligned}
\gamma^{i} u_{T, 0}^{i} & =\gamma^{j} u_{T, 0}^{j} \\
\gamma^{i} u_{T, 0}^{i} & =\underbrace{\gamma^{i} u_{T, 1}^{i}}_{\text {private benefit }}+\underbrace{\gamma^{i} \frac{\partial V^{i}}{\partial M^{i}}+\gamma^{j} \frac{\partial V^{j}}{\partial M^{i}}}_{\text {social benefit of agent } i \text { liquidity }}
\end{aligned}
$$

for $j \neq i$. The intra-temporal condition (17) equates the weighted marginal utility of consumption across agents at time 0 . In the Euler equation (18), the usual consumption smoothing motive - captured by the marginal utilities $u_{T, t}^{i}$ - is complemented by two additional terms that reflect the pecuniary externalities of agent $i$ carrying wealth into period 1 on himself and the other agent.

Using equation (15), the market clearing condition (6), and $\lambda^{S}=0$ since savers are by construction not borrowing-constrained, we rewrite the planner's Euler equation (18) as

$$
\underbrace{\gamma^{i} u_{T, 0}^{i}=\gamma^{i} u_{T, 1}^{i}}_{\text {smoothing consumption }}+\frac{\partial p}{\partial M^{i}}[\underbrace{\left(\gamma^{i} u_{T, 1}^{i}-\gamma^{j} u_{T, 1}^{j}\right)\left(y_{N, 1}^{i}-c_{N, 1}^{i}\right)}_{\text {redistributing between agents }}+\underbrace{\gamma^{B} \lambda^{B} \phi y_{N, 1}^{B}}_{\text {relaxing constraint }}]
$$

The first curly brackets capture the usual consumption smoothing considerations and coincide with the Euler equation of private agents. In addition to this, the planner recognizes

\footnotetext{
${ }^{9}$ The assumption that policymakers cannot directly set exchange rates can be relaxed as long as there is a cost associated with doing so. See, for example, Benigno et al. (2013) for exchange rate intervention. Our basic results continue to hold in these cases. Our assumption is also supported by the experience of many emerging economies that were either forced to abandon nominal pegs or experienced strong real depreciations under fixed nominal exchange rates during crises.
} 
that her allocation of liquid wealth $M^{i}$ affects the real exchange rate and leads to two further effects: a higher exchange rate redistributes from net buyers to net sellers of non-traded goods, as captured by the second curly bracket; furthermore, a higher real exchange rate relaxes the collateral constraint of borrowers, captured by the last term.

Using the terms $R_{i}^{j}$ and $\Phi_{i}^{j}$ for the redistributions and collateral effects of changes in net worth, we can rewrite the equation more compactly as

$$
\gamma^{i} u_{T, 0}^{i}=\gamma^{i} u_{T, 1}^{i}+\left(\gamma^{i} u_{T, 1}^{i}-\gamma^{j} u_{T, 1}^{j}\right) R_{i}^{i}+\gamma^{B} \lambda^{B} \Phi_{i}^{B}
$$

We characterize the solution to the constrained planning problem in the economy as follows:

Proposition 2 (i) Any constrained efficient allocation in the domestic economy satisfies

$$
\begin{aligned}
& \frac{u_{T, 1}^{B}}{u_{T, 0}^{B}}=1-\frac{\lambda^{B}}{u_{T, 0}^{B}} \frac{\Phi_{B}^{B}}{1+R_{B}^{B}-R_{S}^{B}} \\
& \frac{u_{T, 1}^{S}}{u_{T, 0}^{S}}=1-\frac{\lambda^{B}}{u_{T, 0}^{B}} \frac{\Phi_{S}^{B}}{1+R_{B}^{B}-R_{S}^{B}}
\end{aligned}
$$

(ii) In allocations in which the financial constraint is loose, $\lambda^{B}=0$, the planner's optimality conditions coincide with those of decentralized agents.

(iii) In allocations in which the financial constraint is binding, $\lambda^{B}>0$, the planner introduces a wedge in the marginal rate of substitution and acts in a more precautionary manner than private agents in period 0 , i.e. $u_{T, 0}^{i}>u_{T, 1}^{i}$. Furthermore, the wedge is larger for borrowers than for savers.

Proof. For (i), we obtain equations (20) and (21) by combining the planner's Euler equation (19) for both agents to

$$
\gamma^{B} u_{T, 1}^{B}-\gamma^{S} u_{T, 1}^{S}=-\frac{\gamma^{B} \lambda^{B}\left(\Phi_{B}^{B}-\Phi_{S}^{B}\right)}{1+R_{B}^{B}-R_{S}^{B}}
$$

The difference between the weighted marginal utilities of borrowers and savers reflect the difference in how much borrower and saver net worth relax the constraint $\Phi_{B}^{B}-\Phi_{S}^{B}$ normalized by the redistributions created by moving one dollar from savers to borrowers. Substituting this expression back into the Euler equation delivers the result.

For (ii), we observe that the terms on the right-hand side of equations (20) and (21) drops out.

For (iii), notice that all parts of the wedge terms are positive. For $\lambda^{B}$ and $u_{T, 0}^{B}$ this holds by definition; $\Phi_{B}^{B}>\Phi_{S}^{B}>0$ holds because $\partial p / \partial M^{B}>\partial p / \partial M^{S}>0$. Finally, $1+R_{B}^{B}-R_{S}^{B}>0$ by Assumption 2

Intuitively, when the collateral constraint on borrowers is loose, the only pecuniary externalities that appear are the redistributions between borrowers and lenders $R_{i}^{j}$ and the associated allocation is Pareto efficient. This result reflects the standard finding that 
pecuniary externalities cancel out when financial markets are complete, as implied by the first welfare theorem - the gain of one type of agent is the loss of another.

By contrast, when borrowers are constrained, the planner can relax the constraint by shoring up the net worth of both borrowers and savers since both of them consume nontraded goods. Higher net worth during crisis times means that they have more to spend on nontraded goods, which pushes up the real exchange rate and mitigates the contractionary depreciations. The planner introduces a larger wedge in the optimality condition of borrowers since they have a higher marginal propensity to spend.

\subsubsection{Implementation}

Policymakers can replicate any constrained optimal allocation through a combination of taxes and subsidies on borrowers and savers combined with a lump sum transfer. Specifically, assume that policymakers have the ability to impose a tax/subsidy $\tau^{i}$ on the bond purchases and can implement lump-sum transfers $T^{i}$ in period 0 for $i \in\{B, S\}$. The budget constraint of individual agents in period 0 becomes

$$
c_{T, 0}^{i}+\left(1-\tau^{i}\right) b_{1}^{i}+T^{i}=y_{T, 0}^{i}
$$

Specifically, when $b_{1}^{i}>0$ so agent $i$ is a saver, then $\tau^{i}>0$ represents a subsidy to saving. When $b_{1}^{i}<0$ so agent $i$ is a borrower, then $\tau^{i}>0$ constitutes a tax on borrowing. In either case, a positive value for the policy instrument $\tau^{i}$ induces agent $i$ to carry more liquid net worth into the following period. This modifies the private optimization problem of decentralized agents so their Euler equation becomes

$$
\left(1-\tau^{i}\right) u_{T, 0}^{i}=u_{T, 1}^{i}
$$

A policymaker can use these instruments to implement the constrained efficient allocations characterized in Proposition 2 as follows:

Corollary 3 (i) Any constrained efficient equilibrium can be implemented by a pair of taxes $\left(\tau^{B}, \tau^{S}\right)$ with $\tau^{B}>\tau^{S}$ together with lump-sum transfers that satisfy the government budget constraint $T^{B}+T^{S}=\tau^{B} b_{1}^{B}+\tau^{S} b_{1}^{S}$.

(ii) A policymaker can achieve a Pareto improvement on any decentralized equilibrium with binding constraints in which savers achieve utility $U^{S, D E}$ by solving the planning problem

$$
\begin{array}{ll}
\max _{C_{0}^{i}, B_{1}^{i}} u\left(C_{T, 0}^{B}\right)+V^{B}\left(M^{B} ; M^{B}, M^{S}\right) \quad \text { s.t. } & \sum_{i \in\{B, S\}}\left(C_{T, 0}^{i}+B_{1}^{i}-Y_{T, 0}^{i}\right) \leq 0 \\
& u\left(C_{T, 0}^{S}\right)+V^{S}\left(M^{S} ; M^{B}, M^{S}\right) \geq U^{S, D E}
\end{array}
$$

and implementing it using a pair of taxes and lump-sum transfers as described in (i).

Proof. For (i) we observe that the planner can implement a given constrained efficient equilibrium by setting $T^{i}$ such that $c_{T, 0}^{i}+M^{i}+T^{i}=y_{T, 0}^{i}+y_{T, 1}^{i} \forall i$ and setting the pair of taxes equal to

$$
\tau^{B}=\frac{\lambda^{B}}{u_{T, 0}^{B}} \cdot \frac{\Phi_{B}^{B}}{1+R_{B}^{B}-R_{S}^{B}} \quad \tau^{S}=\frac{\lambda^{B}}{u_{T, 0}^{B}} \cdot \frac{\Phi_{S}^{B}}{1+R_{B}^{B}-R_{S}^{B}}
$$


Given these tax rates, the optimality conditions of private agents coincide with the planner's intertemporal optimality conditions (20) and (21).

For (ii), note that if we assign $\gamma^{S}$ as the shadow price on the constraint $U^{S} \geq U^{S, D E}$ and set $\gamma^{B}=1$, then the described optimization problem coincides with the planner's optimization problem (16). In equilibrium, the constraint $U^{S} \geq U^{S, D E}$ will hold with equality and will guarantee that savers are equally well off. Since the initial allocation is feasible for the planner but the planner does not choose it, borrower welfare is strictly higher and the planner's allocation constitutes a Pareto improvement. It can be implemented as described in (i).

How can the tax instruments $\left(\tau^{B}, \tau^{S}\right)$ be mapped into macroprudential regulation and capital controls? As illustrated in Figure 1, capital controls impose a wedge between all domestic agents and foreigners so as to segment domestic and international financial markets. This implies that capital controls increase both $\tau^{B}$ and $\tau^{S}$. By contrast, macroprudential measures increase the rate at which domestic agents borrow but do not affect the rate at which savers lend. Therefore they increase $\tau^{B}$ but do not affect $\tau^{S}$. These considerations imply the following mapping between $\left(\tau^{B}, \tau^{S}\right)$ and $\left(\tau^{C C}, \tau^{M P}\right)$ :

$$
\begin{aligned}
1-\tau^{S} & =\left(1-\tau^{C C}\right) \\
1-\tau^{B} & =\left(1-\tau^{C C}\right)\left(1-\tau^{M P}\right)
\end{aligned}
$$

Corollary 4 The regulated equilibrium described in Corollary 3 can also be implemented by setting the economy's level of capital controls to $\tau^{C C}=\tau^{S}$ and setting the level of macroprudential regulation to fill the gap between $\tau^{S}$ and $\tau^{B}$ so that $1-\tau^{M P}=\left(1-\tau^{B}\right) /\left(1-\tau^{S}\right)$.

Proof. See discussion above.

\subsection{Uncertainty}

This section extends our earlier analysis to explicitly account for uncertainty. Our baseline setup described the simplest framework possible to zero in on the imperfections created by contractionary depreciations by assuming perfect foresight. However, it goes without saying that the occurence of financial crises in practice involves a considerable amount of uncertainty. In this section, we explicitly account for this.

We assume there is a stochastic shock $\omega \in \Omega$ that is realized at the beginning of period 1 and that affects the period 1 traded income of both domestic agents, which we hence denote by $y_{T, 1}^{i}(\omega)$. We assume that the lowest realization $\min \left\{y_{T, 1}^{B}(\omega)\right\}$ is sufficiently low to make the financial constraint on borrowers binding.

In the following, we focus first on the case of complete markets in period 0 in which private agents can make their privately optimal insurance decisions against the stochastic shock $\omega$. Next we will assume that the period 0 financial market is incomplete and domestic agents can only borrow or save in uncontingent bonds. 


\subsubsection{Complete Markets}

We assume that private agents can borrow or save with foreigners in a complete market of Arrow securities in period 0 . We denote the contracted payoff that agent $i$ receives in state of nature $\omega$ by $b_{1}^{i}(\omega)$ and observe that foreigners are willing to sell this payoff at a price of $E\left[b_{1}^{i}(\omega)\right]$ in period 0 . We use our earlier definition of the reduced-form utility $V^{i}(\cdot)$ to express the optimization problem of private agents as

$$
\max _{b_{1}^{i}(\omega)} u\left(y_{T, 0}^{i}-E\left[b_{1}^{i}(\omega)\right]\right)+E\left[V^{i}\left(m^{i}(\omega) ; M^{B}(\omega), M^{S}(\omega)\right)\right]
$$

where $m^{i}(\omega)=y_{T, 1}^{i}(\omega)+b_{1}^{i}(\omega)$ and $\left(M^{B}(\omega), M^{S}(\omega)\right)$ are now stochastic and private agents take the latter as given. Given $m^{i}(\omega)$ and $\left(M^{B}(\omega), M^{S}(\omega)\right)$, the utility of domestic agents and the associated allocations in periods 1 and 2 are fully characterized by the optimization problem $V\left(m^{i} ; M^{B}, M^{S}\right)$ that we defined in section 2.2.

Private agents choose their Arrow security holdings $b_{1}^{i}(\omega)$ according to the standard Euler equation

$$
u_{T, 0}^{i}=u_{T, 1}^{i}(\omega)
$$

They find it optimal to perfectly smooth consumption between periods 0 and 1 and across all states of nature in period 1 , given the risk-neutrality of foreigners and the availability of actuarially fair insurance. However, in states of nature in which the financial constraint is binding, optimal consumption smoothing between periods 1 and 2 is inhibited.

Let us contrast the decentralized equilibrium with the solution chosen by a constrained planner under uncertainty. As before, a constrained social planner maximizes the weighted sum of domestic welfare

$$
\begin{aligned}
& \max _{C_{T, 0}^{i}, B_{1}^{i}(\omega)} \sum_{i \in\{B, S\}} \gamma^{i}\left\{u\left(C_{T, 0}^{i}\right)+E\left[V^{i}\left(m^{i}(\omega) ; M^{B}(\omega), M^{S}(\omega)\right)\right]\right\} \\
& \text { s.t. } \sum_{i \in\{B, L\}}\left(C_{T, 0}^{i}+E\left[B_{1}^{i}(\omega)\right]-Y_{T, 0}^{i}\right) \leq 0 \quad, \quad m^{i}(\omega)=M^{i}(\omega)=Y_{T, 1}^{i}(\omega)+B_{1}^{i}(\omega)
\end{aligned}
$$

The planner's intra- and inter-temporal optimality conditions can be written as a statecontingent version of equations (17) and (18) or (19). The resulting allocations mirror our findings in Proposition 2:

Proposition 5 (Underinsurance) Any constrained efficient allocation in the domestic economy satisfies

$$
\frac{u_{T, 1}^{i}(\omega)}{u_{T, 0}^{i}}=1-\frac{\lambda^{B}(\omega)}{u_{T, 0}^{B}} \frac{\Phi_{i}^{B}(\omega)}{1+R_{B}^{B}(\omega)-R_{S}^{B}(\omega)} \quad \text { for } i \in\{B, S\}
$$

Proof. The proof follows along the same lines as the Proof of Proposition 2.

Equation (26) reflects that the planner does not deviate from the optimal smoothing condition (24) of private agents as long as the financial constraint of borrowers is loose so $\lambda^{B}=0$ and the last term in the equation drops out. However, in states of nature in which 
the financial constraint is binding, $\lambda^{B}>0$, the planner acts in a more precautionary manner and introduces a wedge in the marginal rate of substitution of both sets of private agents in period 0, i.e. $u_{T, 0}^{i}>u_{T, 1}^{i}(\omega)$. As before, the wedge is larger for borrowers than for savers.

Intuitively, the planner insures more against states of nature with binding constraints than private agents. She carries greater net worth for both agents into constrained states of nature in period 1 in order to push up the exchange rate and relax the financial constraint. This creates a deviation from optimal smoothing between periods 0 and 1 in those states but enables better smoothing between periods 1 and 2 .

Our result on underinsurance in the decentralized equilibrium underline that capital controls and macroprudential policy measures need to be sensitive to the riskiness of financial transactions. Uncontingent debt contracts that require repayments even in bad states of nature impose large externalities and call for high levels of regulation, whereas contingent financial instruments that provide insurance (e.g. equity) create much smaller externalities. This mirrors the findings of Korinek $(2010,2011)$ on the desirability of risk-sensitive capital controls and macroprudential regulations.

\subsubsection{Incomplete Markets}

In practice, emerging economies frequently have limited access to insurance instruments against aggregate risk. We capture this in the current subsection by assuming that domestic agents can only borrow or save in uncontingent bonds, even though their traded income $y_{T, 1}^{i}(\omega)$ in period 1 is stochastic.

The optimization problem of domestic agents is identical to problem (23) except that the choice variable is now the uncontingent bond holdings $b_{1}^{i}$ instead of $b_{1}^{i}(\omega)$ so that $m^{i}(\omega)=y_{T, 1}^{i}(\omega)+b_{1}^{i}$ and similarly for $M^{i}(\omega)$. Private agents choose their bond position $b_{1}^{i}$ so as to smooth the expected marginal utility of traded consumption, according to the standard Euler equation

$$
u_{T, 0}^{i}=E\left[u_{T, 1}^{i}(\omega)\right]
$$

The problem of a planner can also be expressed analogously to problem (25) with the uncontingent bond holdings $b_{1}^{i}$ replacing $b_{1}^{i}(\omega)$. The inter-temporal optimality condition of the planner is

$$
\begin{aligned}
& \gamma^{i} u_{T, 0}^{i}=\gamma^{i} E\left[u_{T, 1}^{i}\right]+E\left[\left(\gamma^{i} u_{T, 1}^{i}-\gamma^{j} u_{T, 1}^{j}\right) R_{i}^{i}\right]+\gamma^{B} E\left[\lambda^{B} \Phi_{i}^{B}\right] \\
& =\gamma^{i} E\left[u_{T, 1}^{i}\right]+E\left(\gamma^{i} u_{T, 1}^{i}-\gamma^{j} u_{T, 1}^{j}\right) E\left[R_{i}^{i}\right]+\operatorname{Cov}\left(\gamma^{i} u_{T, 1}^{i}-\gamma^{j} u_{T, 1}^{j}, R_{i}^{i}\right)+\gamma^{B} E\left[\lambda^{B} \Phi_{i}^{B}\right]
\end{aligned}
$$

As in our earlier analysis, saving one additional unit of net worth in period 0 in the uncontingent bond has three effects in period 1: it reduces the expected marginal utility of traded consumption; it leads to a change in the exchange rate and an expected redistribution between the two agents; and it leads to an expected relaxation in the collateral constraint. Notice that we can express the redistributive effect as the sum of the expected redistribution plus a covariance term. To sign the latter, recall that $R_{i}^{B}=\partial p / \partial M^{i} \cdot\left(y_{N, 1}^{B}-c_{N, 1}^{B}\right)$ where $\partial p / \partial M^{B}>0$ is constant. Therefore

$$
\operatorname{Cov}\left(\gamma^{B} u_{T, 1}^{B}-\gamma^{S} u_{T, 1}^{S}, R_{B}^{B}\right)=\partial p / \partial M^{i} \cdot \operatorname{Cov}\left(\gamma^{B} u_{T, 1}^{B}-\gamma^{S} u_{T, 1}^{S}, y_{N, 1}^{B}-c_{N, 1}^{B}\right)
$$


Notice that when borrowers are constrained, both the gap between marginal utilities $\gamma^{B} u_{T, 1}^{B}-$ $\gamma^{S} u_{T, 1}^{S}$ and the amount of their fire sales $y_{N, 1}^{B}-c_{N, 1}^{B}$ are above average and vice versa. Therefore the covariance term is generally positive.

The following proposition characterizes how the planner will optimally intervene in an economy with incomplete markets:

Proposition 6 (Excessive Leverage, Incomplete Markets) Any constrained efficient allocation in the domestic economy with uncertainty and bond markets only satisfies

$$
\frac{E\left[u_{T, 1}^{i}(\omega)\right]}{u_{T, 0}^{i}}=1-\frac{E\left[\lambda^{B}(\omega) \Phi_{i}^{B}(\omega)\right]+\operatorname{Cov}\left(\gamma^{B} u_{T, 1}^{B}(\omega)-\gamma^{S} u_{T, 1}^{S}(\omega), R_{i}^{B}(\omega)\right) / \gamma^{B}}{u_{T, 0}^{B} \cdot\left(1+E\left[R_{B}^{B}(\omega)-R_{S}^{B}(\omega)\right]\right)}
$$

Proof. We combine the inter-temporal optimality conditions (27) for the two agents to find

$$
E\left[\gamma^{B} u_{T, 1}^{B}-\gamma^{S} u_{T, 1}^{S}\right]=-\frac{E\left[\gamma^{B} \lambda^{B}\left(\Phi_{B}^{B}-\Phi_{S}^{B}\right)\right]+\operatorname{Cov}\left(\gamma^{B} u_{T, 1}^{B}-\gamma^{S} u_{T, 1}^{S}, R_{B}^{B}-R_{S}^{B}\right)}{1+E\left[R_{B}^{B}-R_{S}^{B}\right]}
$$

Plugging this expression back into (27) and simplifying terms by using $R_{S}^{B}=R_{B}^{B} / 2$ and $\Phi_{S}^{B}=\Phi_{B}^{B} / 2$ delivers the planner's optimal wedges.

Since the covariance term is positive, the wedge imposed by the planner is greater under incomplete markets than what is suggested by the expected tightness of constraints $E\left[\lambda^{B} \Phi_{B}^{B}\right]$. Intuitively, the covariance term captures that shoring up the net worth of domestic agents has the greatest redistributive effects when borrowers are most constrained since they cannot insure. This increases the incentive of the planner to shore up the net worth of both agents.

\section{Asset Price Externalities}

Borrowing constraints that are linked to asset prices can give rise to vicious cycles and pecuniary externalities similar to those that arise from exchange rate depreciations. We have shown so far that externalities linked to contractionary exchange rate depreciations call for both macroprudential regulation and capital controls. Although such contractionary depreciations are relevant in emerging markets economies (especially those with significant foreign currency debts), they play less of a role in advanced economies. However, advanced economies are nonetheless vulnerable to feedback loops triggered by falling asset prices, tightening collateral constraints, and fire sales, as illustrated in Figure 5. These can also give rise to pecuniary externalities.

This section shows that macroprudential regulation alone is sufficient to address pecuniary externalities linked to fire sales in asset prices. This contrasts with our baseline model in which pecuniary externalities are driven by exchange rate depreciations. The key insight of the section is that fire sales and asset prices are determined solely by the net worth of borrowers; therefore there is no economic rationale for shoring up the net worth of savers, and capital controls are superfluous. 


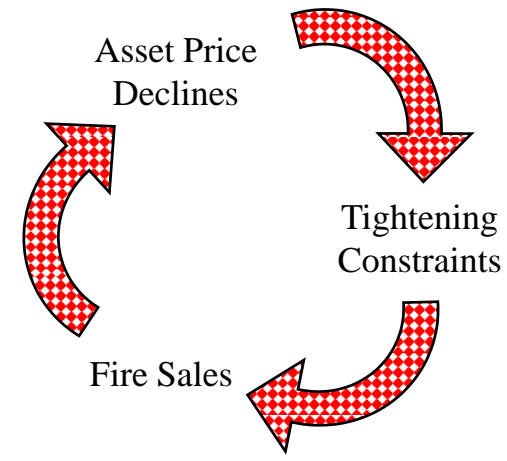

Figure 5: Feedback loop of financial crises with deflation of capital prices

We drop non-traded goods from our baseline model and assume instead that agents obtain an endowment $k_{1}^{i}$ of capital goods that are traded domestically in period 1 and produce output according to a production function $F^{i}\left(k_{2}^{i}\right)$ in period 2. In order to generate the potential for fire sales, we assume that the production function of savers is inferior to that of borrowers. Specifically, we assume $F^{B}\left(k_{2}^{B}\right)=A k_{2}^{B}$ and $F^{S \prime}(0)=A$ but $F^{S \prime \prime}\left(k_{2}^{S}\right)<0$, where we use one and two prime symbols to denote the first and second derivative. In other words, borrowers have a linear production and savers are equally productive in employing the first marginal unit of asset but experience decreasing returns thereafter.

The utility function and the budget constraints of domestic agents $i \in\{B, S\}$ define the following optimization problem:

$$
\begin{aligned}
\max U^{i} \text { s.t. } \quad c_{T, 0}^{i}+b_{1}^{i} & =y_{T, 0}^{1} \\
c_{T, 1}^{i}+b_{2}^{i} & =y_{T, 1}^{1}+q\left(k_{1}^{i}-k_{2}^{i}\right)+b_{1}^{i} \\
c_{T, 2}^{i} & =y_{T, 2}^{i}+F^{i}\left(k_{2}^{i}\right)+b_{2}^{i}
\end{aligned}
$$

where $q$ is the price at which capital goods trade in period 1 so that $q\left(k_{1}^{i}-k_{2}^{i}\right)$ constitutes the revenue derived from fire sales.

We follow Jeanne and Korinek (2010ab) in assuming that borrowers can borrow up to a fraction $\phi$ of the period 1 value of their capital asset holdings,

$$
-b_{2}^{B} \leq \phi q k_{2}^{B}
$$

The first order conditions of private agents include the standard Euler conditions

$$
\begin{aligned}
& u_{T, 0}^{i}=u_{T, 1}^{i} \\
& u_{T, 1}^{i}=u_{T, 2}^{i}+\lambda^{i}
\end{aligned}
$$

and the optimality condition for capital asset purchases, which pins down the price of capital

$$
q=\frac{u_{T, 2}^{i} F^{i \prime}\left(k_{2}^{i}\right)}{(1-\phi) u_{T, 1}^{i}+\phi u_{T, 2}^{i}}=\frac{F^{i \prime}\left(k_{2}^{i}\right)}{\phi+(1-\phi) u_{T, 1}^{i} / u_{T, 2}^{i}}
$$

The price $q$ equals the marginal product of capital discounted by the marginal rate of substitution, where only a fraction $(1-\phi)$ of the asset needs to be financed with period 
1 funds and a fraction $\phi$ can be financed by borrowing from period 2. The asset price is therefore inversely related to consumption growth between period 1 and 2, which reflects the tightness of the borrowing constraint.

\section{Characterizing the Decentralized Equilibrium}

Since savers are unconstrained, it follows that $\lambda^{S}=0$ and $u_{T, 1}^{S}=u_{T, 2}^{S}$. This also implies that savers simply set the marginal product of capital equal to the market price

$$
q=F^{S \prime}\left(k_{2}^{S}\right)
$$

This is an implication of the Fisherian separation between consumption and investment that applies to unconstrained agents. Therefore, changes in the net worth of savers $M^{S}$ have no impact on asset prices

$$
\frac{\partial q}{\partial M^{S}}=0
$$

Similarly, changes in net worth of borrowers $M^{B}$ have no effect on asset prices if the financial constraint is loose. In this case, borrowers purchase the whole stock of capital since they have a better production technology, and the unconstrained asset price is given by $q=A$.

If instead borrowers are constrained, they face a trade-off between consuming and purchasing capital. Savers still set their marginal product of capital equal to $q$, but borrowers reduce capital in proportion to the tightness of the constraint as in equation (28). This generates a reallocation of capital from borrowers to savers which lowers asset prices below their unconstrained level $A$.

As shown in Appendix A.2, an increase in the net worth $M^{B}$ of constrained borrowers leads under mild regularity conditions to higher capital prices,

$$
\frac{\partial q}{\partial M^{B}}>0
$$

Higher net worth raises borrowers' demand for capital that increases asset prices and in turn relaxes borrowing constraints. We summarize the above considerations in the following lemma:

Lemma 7 (i) The asset price $q$ is independent of the liquid net worth $M^{S}$ of savers, i.e. $\partial q / \partial M^{S}=0$.

(ii) As long as borrowers are unconstrained, the asset price equals $q=A$ and is independent of the net worth of borrowers. If borrowers are constrained, the asset price is an increasing function of the liquid net worth of borrowers,

$$
\frac{\partial q}{\partial M^{B}}>0
$$

Proof. See discussion above.

When borrowers are constrained, an increase in $M^{B}$, by rising asset prices, triggers redistributive effects and relaxes the borrowing constraint. The redistributive effect on borrowers is captured by:

$$
R_{B}^{B}=\frac{\partial q}{\partial M^{B}}\left(k_{1}^{B}-k_{2}^{B}\right)
$$


which is positive if borrowers are net sellers of capital and negative otherwise. Similarly to the model with exchange rate externalities, we assume

Assumption $31+R_{B}^{B}>0$

This ensures that providing one extra dollar to borrowers does not immiserize them by reducing their wealth through large negative redistributive effects. The impact of higher $M^{B}$ on the borrowing constraint is captured by

$$
\Phi_{B}^{B}=\frac{\partial q}{\partial M^{B}} \phi k_{2}^{B}>0
$$

\section{Characterizing the Planner Solution}

The setup of the planner's problem is analogous to the one described in section 2.3. In choosing the Pareto efficient allocation, the planner takes into account that changes in $M^{S}$ have no effect on asset prices, and thus do not trigger redistributive effects, $R_{S}^{B}=0$, and do not affect borrowing constraints, $\Phi_{S}^{B}=0$. The planner has therefore no reason to distort savers' intertemporal decisions and the planner's Euler equation for savers is identical to the laissez-faire optimality condition:

$$
u_{T, 0}^{S}=u_{T, 1}^{S}
$$

However, the planner still intervenes in the financial decisions of borrowers when the constraint is binding. Greater liquidity $M^{B}$ increases borrowers' demand for capital and raises asset prices. The planner's Euler equation for borrowers (20) is:

$$
u_{T, 0}^{B}=u_{T, 1}^{B}+\lambda^{B} \frac{\Phi_{B}^{B}}{1+R_{B}^{B}}
$$

Given Assumption 3 and $\lambda^{B} \Phi_{B}^{B}>0$, the planner's wedge raises $u_{T, 0}^{B} / u_{T, 1}^{B}$ which limits borrowing at time 0 .

The social planner thus shores up the liquid net worth of borrowers so as to reduce asset fire sales without distorting the inter-temporal decisions of lenders. Intuitively, this is because an increase in the net worth of borrowers supports asset prices and relaxes borrowing constraints, whereas the net worth of savers is inconsequential for asset prices. The willingness of savers to purchase assets in period 1 depends on their production function and on the interest rate at which they are able to fund asset purchases, which is determined on world markets and does not depend on their net worth since savers are unconstrained. Therefore there is no reason for the planner to distort their intertemporal allocation in period 0 .

Corollary 8 (Asset Price Externalities) In a model in which financial constraints are linked to asset prices, a planner imposes macroprudential restrictions on borrowers,

$$
\tau^{M P}=\tau^{B}=\frac{\lambda^{B}}{u_{T, 0}^{B}} \cdot \frac{\Phi_{B}^{B}}{1+R_{B}^{B}}>0,
$$

but does not impose capital controls so $\tau^{C C}=\tau^{S}=0$.

Proof. See discussion above and Corollary 4. 


\section{Conclusions}

This paper analyzes the benefits and costs of capital controls versus macroprudential regulation in reducing financial fragility. Our main finding is that both instruments play distinct roles. We develop a stylized model in which a planner finds it optimal to impose both capital controls and macroprudential regulation when we calibrate it to reflect the typical conditions of emerging economies. By imposing capital controls, she raises the net worth of both domestic borrowers and savers. By imposing macroprudential regulation, she raises the net worth of borrowers even further, which is desirable because constrained borrowers have a higher marginal propensity to consume than unconstrained savers.

When our model is calibrated to reflect conditions in advanced economies, where exchange rate fluctuations are less destabilizing, we still find a role for policy intervention in order to avoid boom and bust cycles in asset prices. To address these externalities, a planner in our model finds it optimal to increase the net worth of domestic borrowers, but has no reason to intervene on domestic savers because the net worth of domestic savers has no influence on their demand for capital and thus on asset prices because of the Fisherian separation between consumption and investment decisions. Macroprudential regulation is thus sufficient to deal with externalities linked to asset prices.

There are a number of issues that are beyond the scope of the current paper. First, our paper distinguishes between capital controls and macroprudential regulation based on one specific dimension along which borrowing from foreign and domestic lenders differs the pecuniary externalities on exchange rates that they generate. Although contractionary movements in exchange rates are of utmost importance during financial crises, there is a range of additional dimension that are relevant. For example, borrowing from domestic and foreign lenders likely leads to different bailout and risk-shifting probabilities and generates different incentive effects. They also lead to different aggregate demand effects. Furthermore, when interacting with international lenders, considerations about market power that are absent in domestic lending relationships may come into play. Finally, it may be desirable to regulate borrowing from domestic or foreign lenders differently when the residency of the lender correlates with features that cannot be directly observed, such as the flightiness of funds, or that cannot be targeted directly because restrictions on regulatory instruments. These considerations are analyzed in detail in Ostry et al. (2014).

Secondly, there are additional policy measures that have sometimes been used in a prudential manner. For example, reserve accumulation may be helpful to stem real appreciation if international capital markets are sufficiently segmented to prevent arbitrage; contractionary monetary policy may be able to prick bubbles; fiscal consolidation may prevent an economy from overheating. Ostry et al. (2010) and Blanchard et al. (2014) discuss several of these options. However, following the principle that a distortion is best addressed directly at its source, capital controls or macroprudential regulation may be better-suited than other instruments to deal with the pecuniary externalities generated by financial crises. For example, Korinek and Simsek (2014) show that monetary policy is not a well-suited instrument to stem against excessive leverage.

Thirdly, our paper focuses on prudential interventions to mitigate crisis risk, i.e. policy measures that are taken in good times in order to reduce the risk and magnitude of crises in response to bad shocks in the future. There is a complementary literature that focuses 
on ex-post policy measures (see e.g. Benigno et al., 2013; Jeanne and Korinek, 2013) that are taken if a country experiences a financial crisis. This is particularly relevant for the analysis of capital controls since many countries (including e.g. Iceland and Cyprus) have used controls on outflows as a crisis management tool.

\section{References}

Alfaro, Laura, Anusha Chari and Fabio Kanczuk, 2014, "The Real Effects of Capital Controls: Liquidity Constraints and Firm Investment," manuscript, Harvard.

Benigno, Gianluca, Huigang Chen, Christopher Otrok, Alessandro Rebucci, and Eric R. Young, 2012, "Optimal Policy for Macro-Financial Stability," manuscript, LSE.

Bianchi, Javier, 2011, "Overborrowing and Systemic Externalities in the Business Cycle," American Economic Review 101(7), pp. 3400-3426.

Bianchi, Javier, and Enrique Mendoza, 2013, "Optimal Time-Consistent Macroprudential Policy in a Model of Overborrowing and Financial Crises," manuscript, University of Pennsylvania.

Blanchard, Olivier J., Jonathan D. Ostry, Atish R. Ghosh, and Marcos Chamon, 2014, "Capital Flow Management," manuscript.

Caballero, Ricardo J., and Arvind Krishnamurthy, 2003, "Excessive Dollar Borrowing: Financial Development and Underinsurance," Journal of Finance 58(2), pp. 867-894.

Claessens, Stijn, Swatish R. Ghosh, Roxana Mihet, 2013, "Macro-Prudential Policies to Mitigate Financial System Vulnerabilities," Journal of International Money and Finance 39, pp. 153-185.

Farhi, Emmanuel and Iván Werning, 2012, "Dealing with the Trilemma: Optimal Capital Controls with Fixed Exchange Rates," NBER Working Paper w18199.

Farhi, Emmanuel and Iván Werning, 2013, "A Theory of Macroprudential Policies in the Presence of Nominal Rigidities," NBER Working Paper w19313.

Farhi, Emmanuel and Iván Werning, 2014, "Dilemma not Trilemma? Capital Controls and Exchange Rates with Volatile Capital Flows," manuscript, Harvard.

Federico, Pablo M., Carlos A. Végh and Guillermo Vuletin, 2013, "Effects and Role of Macroprudential Policy: Evidence from Reserve Requirements Based on a Narrative Approach," manuscript, Johns Hopkins University.

Forbes, Kristin, Marcel Fratzscher and Roland Straub, 2013, "Capital Controls and Macroprudential Measures: What Are They Good For?" DIW Discussion Paper 1343.

Galati, Gabriele, and Richhild Moessner, 2013, "Macroprudential policy - a literature review, "Journal of Economic Surveys 27(5), pp. 846-878.

IMF, 2012, The Liberalization and Management of Capital Flows: An Institutional View, Washington, DC. 
Jeanne, Olivier, 2014, "Macroprudential Policies in a Global Perspective," NBER Working Paper w19967.

Jeanne, Olivier, and Anton Korinek, 2010a, "Excessive Volatility in Capital Flows: A Pigouvian Taxation Approach," American Economic Review PESP, pp. 403-407.

Jeanne, Olivier, and Anton Korinek, 2010b, "Managing Credit Booms and Busts: A Pigouvian Taxation Approach," NBER Working Paper w16377.

Jeanne, Olivier, and Anton Korinek, 2013b, "Macroprudential Regulation versus Mopping Up After the Crash," NBER Working Paper w18675.

Keynes, John M., 1929, "The German Transfer Problem," Economic Journal 39(1929), pp. $1-7$.

Korinek, Anton, 2007, "Excessive Dollar Borrowing in Emerging Markets," manuscript, University of Maryland.

Korinek, Anton, 2010, "Regulating Capital Flows to Emerging Markets: An Externality View," manuscript, University of Maryland.

Korinek, Anton, 2011a, "The New Economics of Prudential Capital Controls," IMF Economic Review 59(3), pp. 523-561.

Korinek, Anton, 2011b, "Systemic Risk-Taking: Amplification Effects, Externalities, and Regulatory Responses," ECB Working Paper 1345.

Korinek, Anton and Alp Simsek, 2014, "Liquidity Trap and Excessive Leverage," NBER Working Paper w19970.

Lorenzoni, Guido, 2008, "Inefficient Credit Booms," Review of Economic Studies 75(3), pp. 809-833.

Magud, Nicolas E., Carmen M. Reinhart, and Kenneth S. Rogoff, 2011, "Capital Controls: Myth and Reality - A Portfolio Balance Approach," NBER Working Paper w16805.

Mendoza, Enrique G., 2002, "Credit, Prices and Crashes: Business Cycles with a Sudden Stop," in S. Edwards and J. Frankel (editors), Preventing Currency Crises in Emerging Markets, pp. 335-392, NBER, University of Chicago Press.

Ohlin, Bertil, 1929, "The German Transfer Problem: A Discussion," Economic Journal 39(1929), pp. 172-182.

Ostry, Jonathan D., Atish R. Ghosh, Karl Habermeier, Marcos Chamon, Mahvash S. Qureshi and Dennis B.S. Reinhardt, 2010, "Capital Inflows: The Role of Controls," IMF Staff Position Note 10/04.

Ostry, Jonathan D., Atish R. Ghosh, Karl Habermeier, Luc Laeven, Marcos Chamon, Mahvash S. Qureshi and Annamaria Kokenyne (2011), "Managing Capital Inflows: What Tools to Use?" IMF Staff Discussion Note 11/06.

Ostry, Jonathan D., Atish R. Ghosh and Anton Korinek (2014), tbd.

Schmitt-Grohe, Stephanie and Martin Uribe, 2012, "Prudential Policy for Peggers," NBER Working Paper w18031. 


\section{A Mathematical Appendix}

\section{A.1 Model with Non-Traded Goods}

The technical condition that characterizes the upper limit $\hat{\phi}$ on the pledgeability parameter in the model with non-traded goods is

$$
Y_{N, 1}-(1-\alpha)\left[Y_{N, 1}^{B}(1+\hat{\phi})+Y_{N, 1}^{S} / 2\right]=0
$$

Given this definition, the assumption $\phi<\hat{\phi}$ implies that the denominator $D$ in expression (14) is strictly positive so as to avoid degenerate equilibria.

The unconstrained region, i.e. the set of $\left(M^{B}, M^{S}\right) \in \mathcal{M}^{u n c}$, is determined by the fact that the borrowing level that ensures full consumption smoothing is no greater than the constrained limit:

$$
\frac{1}{2}\left(M^{B}+p Y_{N, 1}^{B}-Y_{T, 2}^{B}\right) \geq-\phi\left(Y_{T, 1}^{B}+p Y_{N, 1}^{B}\right)
$$

By substituting out the definition of the price level in the unconstrained region:

$$
p=\frac{1-\alpha}{1+\alpha}\left(M^{B}+M_{S}+Y_{T, 2}\right)
$$

where $Y_{T, 2}=Y_{T, 2}^{B}+Y_{T, 2}^{S}$, we can derive the following inequality that pins down the set $\left(M^{B}, M^{S}\right) \in \mathcal{M}^{\text {unc }}$

$$
\begin{aligned}
M^{B}\left(\frac{1}{2}+Y_{N, 1}^{B} \frac{1-\alpha}{1+\alpha}\left(\frac{1}{2}+\phi\right)\right)+M^{S} Y_{N, 1}^{B} \frac{1-\alpha}{1+\alpha}\left(\frac{1}{2}+\phi\right) \geq & \\
& \frac{Y_{T, 2}^{B}}{2}-\phi Y_{T, 1}^{B}-Y_{T, 2} Y_{N, 1}^{B} \frac{1-\alpha}{1+\alpha}\left(\frac{1}{2}+\phi\right)
\end{aligned}
$$

\section{A.2 Model with Capital Goods}

To analyze how $M^{B}$ affects the price of capital goods when borrowers are constrained, consider that savers set their marginal product of capital equal to the price $q$. Using the fact that $K_{2}^{S}=K-K_{2}^{B}$, where $K$ is the total stock of capital, we infer that

$$
\frac{\partial q}{\partial M^{B}}=-F^{S \prime \prime} \frac{\partial K_{2}^{B}}{\partial M^{B}}
$$

Since $F^{S \prime \prime}<0$, we see that $\partial q / \partial M^{B}>0$ if and only if $\partial K_{2}^{B} / \partial M^{B}>0$. This latter derivative can be analyzed by considering that the optimality condition (28) implies

$$
F^{S \prime}=\frac{F^{B \prime}}{\phi+(1-\phi) u_{T, 1}^{B} / u_{T, 2}^{B}}
$$

where the consumption levels of constrained borrowers are given by:

$$
\begin{aligned}
& C_{T, 1}^{B}=M^{B}+q\left(K_{1}^{B}-K_{2}^{B}\right)+\phi\left(Y_{T, 1}^{B}+q K_{2}^{B}\right) \\
& C_{T, 2}^{B}=F^{B}+Y_{T, 2}^{B}-\phi\left(Y_{T, 1}^{B}+q K_{2}^{B}\right)
\end{aligned}
$$


By using the implicit function theorem, we can show that

$$
\frac{\partial K_{2}^{B}}{\partial M_{2}^{B}}>0
$$

under the following (sufficient but not necessary) conditions:

$$
\begin{aligned}
& \frac{\partial C_{T, 1}^{B}}{\partial K_{2}^{B}}=-F^{S \prime \prime}\left(K_{1}^{B}-K_{2}^{B}+\phi K_{2}^{B}\right)-F^{S \prime}(1-\phi)<0 \\
& \frac{\partial C_{T, 2}^{B}}{\partial K_{2}^{B}}=A-\phi\left(-F^{S \prime \prime} K_{2}^{B}+F^{S \prime}\right)>0
\end{aligned}
$$

The first condition implies that an increase in $K_{2}^{B}$ should come at the cost of a reduction in $C_{T, 1}^{B}$. This requires placing an upper bound on the collateral parameter $\phi$ and ensuring that the second derivative of the savers' production function is not too high in order to limit the responsiveness of prices to the demand for capital. The second condition requires that a marginal increase in $K_{2}^{B}$ leads to greater net worth at time 2 and thus higher $C_{T, 2}^{B}$. This condition also places an upper bound on $\phi$. 